\title{
Acid Pickling Process of Titanium alloys and its Investigation of intergranular corrosion and Pitting corrosion
}

\author{
YOU Li-mei ${ }^{1, ~ a ~, ~ P E N G ~ D o n g-q i a n g ~}{ }^{2, b}$, ZHOU Lin-yan $^{2, c}$, Li Feng ${ }^{1, d}$, ZHAO

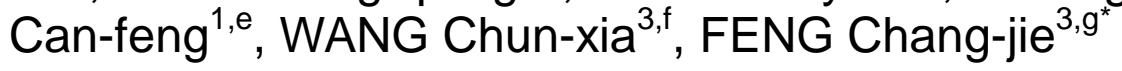

${ }^{1}$ Heat \& Surface Treatment Plant, AVIC Jiangxi Hongdu Aviation Industry Group Co., Ltd., Nanchang 330024 China

${ }^{2}$ Department of Manufacturing Engineering, AVIC Jiangxi Hongdu Aviation Industry Group Co., Ltd., Nanchang 330024 China

${ }^{3}$ School of Materials Science and Engineering, Nanchang Hangkong University, Nanchang 330063 China)

a75676707@qq.com, bpdongqiang@126.com, 'zhouly@126.com, d794238459@qq.com, ezhaocanfeng@139.com, ${ }^{\dagger}$ wangchx@126.com, ${ }^{9}$ chjfengniat@126.com

Keywords: Acid Pickling Process; Titanium alloys; Intergranular corrosion; Pitting corrosion Abstract. Before fluorescence detection of Titanium alloy components, acid pickling in HF-HNO3 solutions is always required in order to remove the superficial oxides of the components. According to the relative CPS document, the conditions for Titanium alloy pickling are HF arranged below 90g/L, HNO3 300-450g/L and at ambient temperature. In this paper, the corrosion rate of the acid pickling process of TC4 alloy was investigated using the acid solutions with variable HF、Titanium contents and fixed $\mathrm{HNO} 3$ content of $375 \mathrm{~g} / \mathrm{L}$ at different temperatures. In addition, the intergranular corrosion and pitting corrosion of the TC4 alloys after pickling under different conditions were conducted. The effects of HF and $\mathrm{HNO} 3$ on the intergranular corrosion and pitting corrosion were discussed.

\section{Introduction}

Due to their high specific strength, excellent corrosion resistance and welding properties, titanium alloys are widely used in industries ${ }^{[1,2]}$. Fluorescence detection of Titanium alloy components has become a usual method to examine their quality. Before the fluorescence detection, acid pickling is the most important process in order to remove the superficial oxides of the components.

Acid pickling of the Titanium alloys are widely investigated at home and abroad ${ }^{[3,4]}$. $\operatorname{Rudy}^{[4]}$ reported the effects of $\mathrm{HF} 、 \mathrm{HNO}_{3} 、 \mathrm{H}_{2} \mathrm{SO}_{4}$ and $\mathrm{H}_{3} \mathrm{PO}_{4}$ on the surface microstructure, roughness and hydrogen content of the titanium alloys after acid pickling in detail. Ogawa et al ${ }^{[5]}$ found that, when the titanium alloy was immersed in HF solutions, it contained more hydrogen as the time increases. Besides, the hydrogen concentration in the alloy increased with the HF content in the pickling solution ${ }^{[6]}$. Vermesse et. al. ${ }^{[7]}$ concluded that the surface quality and fatigure properties of the Ti-6Al-4V alloy can meet the requirements of the aviation industry when the acid pickling solutions contain $\mathrm{HNO}_{3}$ below $20 \%$ and $\mathrm{HF}$ below $2.5 \%$.

According to the relative CPS document, the conditions for Titanium alloy pickling are HF arranged below $90 \mathrm{~g} / \mathrm{L}, \mathrm{HNO}_{3} 300-450 \mathrm{~g} / \mathrm{L}$ and at ambient temperature. The document is relatively simple and always causes troubles when the acid pickling conditions changes for the removal amount is fixed, while the corrosion rate is variable.

In this paper, the corrosion rate of the acid pickling process of TC4 alloy was investigated 
using the acid solutions with variable $\mathrm{HF}$ 、 Titanium contents and fixed $\mathrm{HNO}_{3}$ content of $375 \mathrm{~g} / \mathrm{L}$ at $10^{\circ} \mathrm{C} 、 20^{\circ} \mathrm{C} 、 30^{\circ} \mathrm{C}$ and $38^{\circ} \mathrm{C}$ temperatures. Besides, the intergranular corrosion and pitting corrosion of the TC4 alloys after pickling under different conditions were conducted. The effects of $\mathrm{HF}$ and $\mathrm{HNO}_{3}$ on the intergranular corrosion and pitting corrosion were also discussed.

\section{Experimental}

Calculation of corrosion rate. The TC4 samples are about $51 \mathrm{~mm} \times 51 \mathrm{~mm} \times 3 \mathrm{~mm}$, and the immersion time is $15 \mathrm{~min}$. Before and after the acid pickling, the weight, size and thickness values of the samples are strictly measured by electronic balance, vernier caliper and micrometer caliper, respectively. The corrosion rate of the samples can be calculated by the following formula.

$$
V=\frac{4\left(m_{1}-m_{2}\right) v}{A * m_{1}}
$$

That is, $V$ : corrosion rate, $\mathrm{mm} / \mathrm{side} / \mathrm{h} ; m_{1}$ : original weight, $\mathrm{g} ; m_{2}$ : weight after pickling, $\mathrm{g} ; v$ : original volume of the sample, $\mathrm{mm}^{3} ; A$ total original surface area, $\mathrm{mm}^{2}$.

Acid pickling process. The acid pickling solutions are prepared using analytical reagent HF、 $\mathrm{HNO}_{3} 、 \mathrm{H}_{2} \mathrm{TiF}_{6}$ and purified water, and the solutions contain fixed $\mathrm{HNO}_{3}$ content of $375 \mathrm{~g} / \mathrm{L}$, fixed Titanium content of 5 or $15 \mathrm{~g} / \mathrm{L}$, variable HF content arranged $20-50 \mathrm{~g} / \mathrm{L}$. The total volume of the acid solution is $2 \mathrm{~L}$. The pickling experiments were conducted at $10^{\circ} \mathrm{C} 、 20^{\circ} \mathrm{C} 、 30^{\circ} \mathrm{C}$ and $38^{\circ} \mathrm{C}$ temperatures. For insurance, the solutions are set in water bath of the constant temperature freezer.

Intergranular corrosion and pitting corrosion. Polished samples are prepared to conduct the intergranular corrosion and pitting corrosion tests. The corrosion depths of the samples were about $12 \mathrm{~m}$ and corrosion conditions is listed in Table 1. The cross-sectional morphologies of the tested samples were observed by a XJP-6A optical microscope at the magnification of 600 .

Table 1 The conditions of intergranular corrosion and pitting corrosion

\begin{tabular}{|c|c|c|c|c|}
\hline \multirow{2}{*}{$\begin{array}{c}\text { Experiment serial } \\
\text { number }\end{array}$} & \multicolumn{3}{|c|}{ Acid pickling conditions $/(\mathrm{g} / \mathrm{L})$} & \multirow{2}{*}{ temperature $/{ }^{\circ} \mathrm{C}$} \\
\cline { 2 - 5 } & $\mathrm{Ti}$ & $\mathrm{HF}$ & $\mathrm{HNO}_{3}$ & \\
\hline 1 & 10 & 30 & 450 & 10 \\
\hline 2 & 10 & 30 & 300 & 10 \\
\hline 3 & 10 & 90 & 300 & 10 \\
\hline 4 & 10 & 90 & 300 & 38 \\
\hline 5 & 10 & 30 & 300 & 38 \\
\hline 6 & 10 & 90 & 450 & 38 \\
\hline
\end{tabular}




\section{Results and discussion}

The corrosion rate of the TC4 alloy at different conditions are shown in Fig.1.
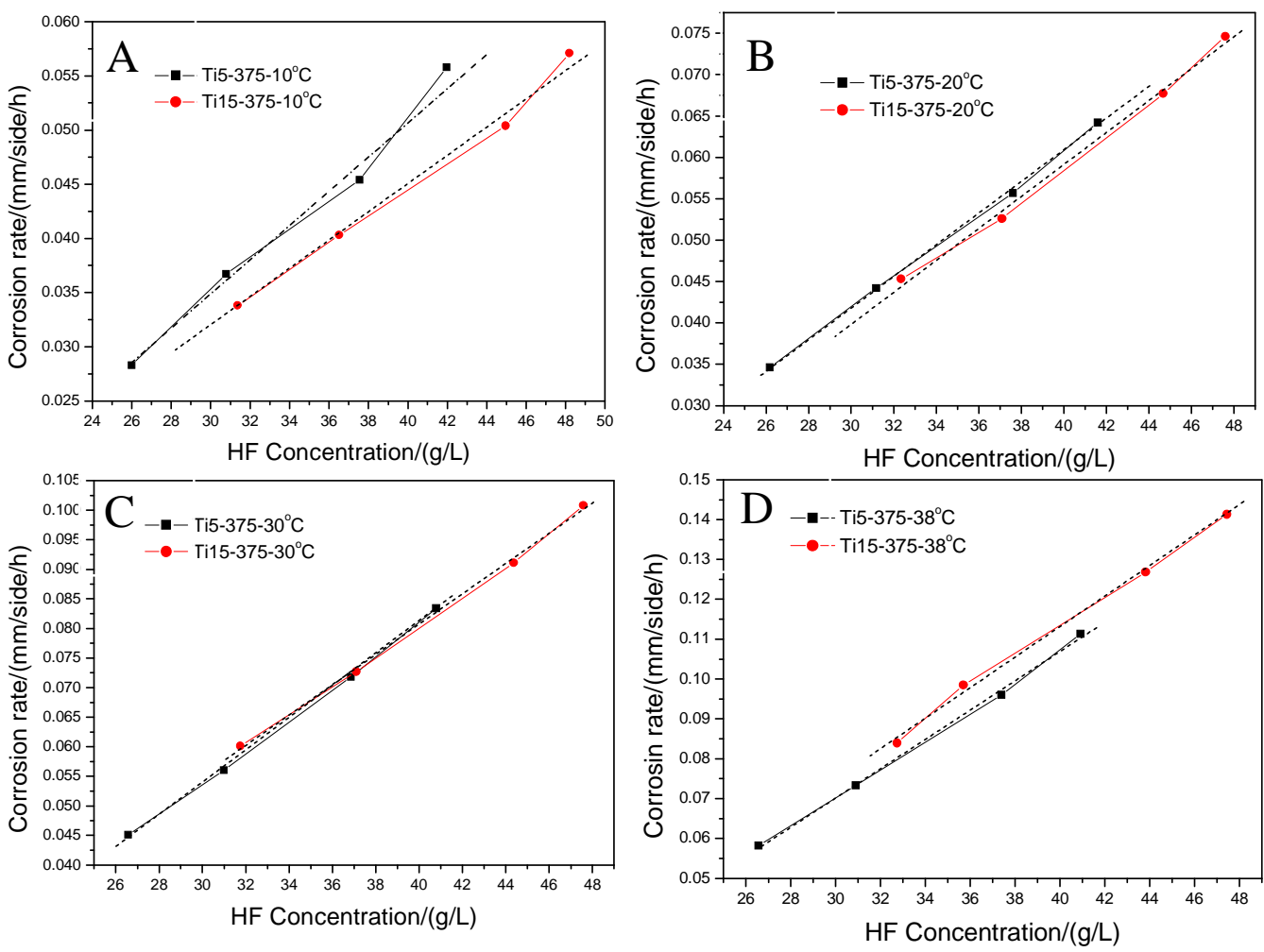

Fig. 1 the corrosion rates of TC4 alloy under different conditions. A: $10^{\circ} \mathrm{C} ; \mathrm{B}: 20^{\circ} \mathrm{C} ; \mathrm{C}: 30^{\circ} \mathrm{C} ; \mathrm{D}: 38^{\circ} \mathrm{C}$

From Fig.1, it can be seen that, with the temperature and HF concentration increased, the corrosion rate increased. The $\mathrm{HNO}_{3}$ content in the solutions also has influence on the corrosion rate. At low temperature, the corrosion rate of the solution with $15 \mathrm{~g} / \mathrm{L} \mathrm{Ti}$ ions is much smaller than that of containing $5 \mathrm{~g} / \mathrm{L}$, as seen in Fig.1A. While, with temperature increased, the difference of corrosion rate between them became narrower, seeing in Fig1B and $\mathrm{C}$. When the corrosion temperature was $38{ }^{\circ} \mathrm{C}$ as shown in Fig. $1 \mathrm{D}$, the corrosion rate of the solution with $15 \mathrm{~g} / \mathrm{L}$ Ti ions is apparently higher than that of containing $5 \mathrm{~g} / \mathrm{L}$. This phenomenon may be ascribed to the passivation effects of $\mathrm{HNO}_{3}$, which is much more intensive at low temperature than at high temperature.

The typical intergranular corrosion and pitting corrosion morphologies after are shown in Fig.2, and the summaries of the values of intergranular and pitting corrosion are shown inTable. 2 . 


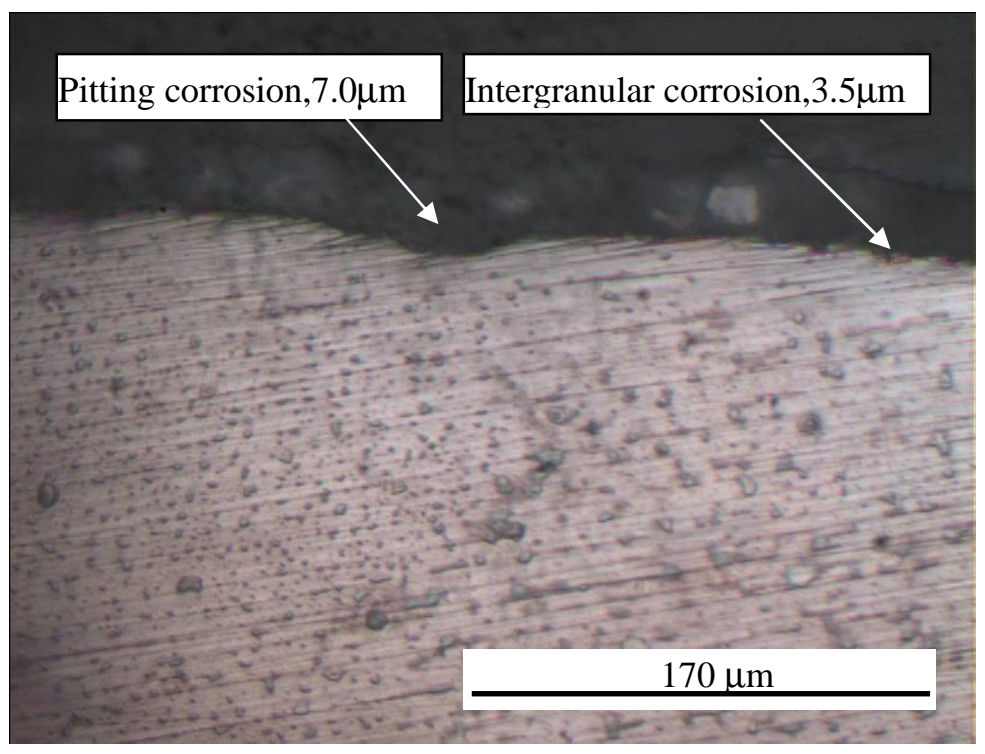

Fig.2 Typical intergranular corrosion and pitting corrosion of the TC4 alloy after pickling

It can be found from Table. 2 that, at low temperature, the average intergranular corrosion depth decreased from 7.2 to $3.5 \mu \mathrm{m}$ as the $\mathrm{HNO}_{3}$ concentration increased from 300 to $450 \mathrm{~g} / \mathrm{L}$. As the $\mathrm{HF}$ concentration increased, the average pitting corrosion depth slightly increased. The effects of $\mathrm{HNO}_{3}$ and $\mathrm{HF}$ can also be found for pickling at $38^{\circ} \mathrm{C}$.It may be summarized the $\mathrm{HNO}_{3}$ can restrain the growth of intergranular corrosion, while the HF promote the pitting corrosion during acid pickling.

Table.2 Results of intergranular corrosion and pitting corrosion

\begin{tabular}{|c|c|c|c|c|c|c|c|c|}
\hline \multirow{2}{*}{$\begin{array}{l}\text { Experiment } \\
\text { serial number }\end{array}$} & \multicolumn{3}{|c|}{ Acid pickling conditions $/(\mathrm{g} / \mathrm{L})$} & \multirow{2}{*}{$\begin{array}{l}\text { Temper- } \\
\text { ature } /{ }^{\circ} \mathrm{C}\end{array}$} & \multirow{2}{*}{$\begin{array}{c}\text { A:Intergranular } \\
\text { corrosion depth } / \mu \mathrm{m}\end{array}$} & \multirow{2}{*}{$\begin{array}{l}\text { Average } \\
\text { of } \mathrm{A} / \mu \mathrm{m}\end{array}$} & \multirow{2}{*}{$\begin{array}{c}\text { B:Pitting corrosion } \\
\text { depth } / \mu \mathrm{m}\end{array}$} & \multirow{2}{*}{$\begin{array}{l}\text { Average } \\
\text { of } \mathrm{B} / \mu \mathrm{m}\end{array}$} \\
\hline & $\mathrm{Ti}$ & $\mathrm{HF}$ & $\mathrm{HNO}_{3}$ & & & & & \\
\hline 1 & 10 & 30 & 450 & 10 & $3.8,2.2,2.8,5.0$ & 3.5 & $5.9,8.8,6.0,7.3,10.7$ & 7.7 \\
\hline 2 & 10 & 30 & 300 & 10 & $\begin{array}{c}8.6,5.8,5.2,7.5,6.6 \\
7.6,9.2\end{array}$ & 7.2 & $4.3,3.9$ & 4.1 \\
\hline 3 & 10 & 90 & 300 & 10 & $4.3,3.6,3.5,6.0$ & 4.4 & $6.1,7.0,4.5,2.9$ & 5.1 \\
\hline 4 & 10 & 90 & 300 & 38 & $\begin{array}{c}5.7,7.4,5.6,4.8,6.7 \\
9.2,10.5\end{array}$ & 7.1 & $\begin{array}{c}9.4,11.1,6.7,18.1 \\
10.7\end{array}$ & 11.2 \\
\hline 5 & 10 & 30 & 300 & 38 & $5.0,6.6$ & 5.8 & $3.4,3.7,5.1,4.1$ & 4.1 \\
\hline 6 & 10 & 90 & 450 & 38 & $6.3,4.3$ & 5.3 & $\begin{array}{c}5.6,3.5,2.2,3.4,9.4 \\
6.7\end{array}$ & 5.1 \\
\hline
\end{tabular}

\section{Conclusion}

$\mathrm{HF}$ can promote the acid pickling rate apparently, while the effects of $\mathrm{HNO}_{3}$ and $\mathrm{Ti}$ are opposite. The passivation effects of $\mathrm{HNO}_{3}$ decreases as the pickling temperature increases.

$\mathrm{HNO}_{3}$ can restrain the growth of intergranular corrosion, while the HF promote the pitting corrosion during acid pickling.

\section{References}

[1] Anon. Titanium alloys for aerospace. Advance Material Process. 1999, 155( 3) : 39. 
[2] Lineberger, Lane. Titanium aerospace alloys. Advance Material Process, 1998, 153( 5) : 45.

[3] Michael Murphy. Pickling and descaling, J. Metal Finishing, 1996, 94: 18-26.

[4] Stephen F. Rudy. Pickling and acid dipping, J. Metal Finishing, 2001, 99:183-190.

[5] T. Ogawa, K. Yokoyama, K. Asaoka. Sakai.Hydrogen absorption behavior of beta titanium alloy in acid fluoride solutions, J. Biomaterials,2004,25:2419-2425.

[6] P.F.A. Bijlmer. Pickling titanium in hydrofluoric-nitric acid, J. Metal Finishing, 1970,68:64-72.

[7] Eric Vermesse, Catherine Mabru, Laurent Arurault. Surface integrity after pickling and anodization of Ti-6Al-4V tatanium alloy, J. Applied Surface Science, 2013, 285: 629-637. 